\title{
Laboratory and Field Investigations of Generator Stator Insulation
}

\author{
M.A.R.M. Fernando and G.A. Jayantha
}

\begin{abstract}
This paper presents the condition assessment of synchronous generator stator insulation used in Sri Lankan power stations. The work has three parts i.e. theoretical, laboratory and field investigations. In the first part, theory behind dielectric insulations have been broadly discussed with the aid of different non-destructive test methods used to asses the conditions of the generator insulation. In the laboratory investigations, two naturally wetted asphalt mica, one dry polyester mica and one dry epoxy mica spare stator windings were tested under drying and wetting conditions. The used test methods were DC ramp, time variation of insulation resistance (IR), polarization and depolarization current (PDC), frequency dielectric spectroscopy (FDS) and partial discharge (PD) tests and the relationships have been established among them. In the field investigations, different generators belonging to Ceylon Electricity Board were tested by using DC ramp test. It was found that the DC ramp test, as an easy and simple field test, can be effectively used to investigate the moisture effect on generator insulation.
\end{abstract}

Key words: Synchronous generator, Stator insulation, moisture, condition assessment, DC ramp test, Frequency dielectric spectroscopy

\section{Introduction}

Generator stator winding insulation is exposed to Thermal, Electrical, Mechanical and Environmental stresses during the operation, and failure of winding insulation depends on combination of these stresses. Major failure modes of the winding insulation can be due to internal partial discharges, thermal cycling or overloading, ageing, loosening of bars in the slot or winding overhangs, over voltages, and contamination. Out of them, contamination of the stator insulation is responsible for about $25 \%$ of the major failures and it is mainly due to moisture absorption within or outside from the generator. Due to hygroscopic nature of many type of the insulation systems moisture can be drawn into the body of the insulation from the atmospheric air or from leakage of water from the coolers of the generator stator. Thus this absorbed moisture has a greater effect on properties of the insulation. In addition, moisture in combination with oil, carbon dust and brake dust which are already deposited on the winding insulation and ventilation paths can accelerate thermal deterioration or thermal ageing of the generator stator winding insulation and stator core. Humidity dependency on the insulation properties seems to be associated with specific stator winding deterioration process such as electrical tracking and end winding partial discharge activities [1].
There are various on-line and off-line test methods used by the engineers for diagnosing condition of the stator winding insulation of the generators in operation [2]. Assessing the remaining life time, deciding the priority level for next major maintenance and determining the root cause for the failure of the failed winding are the main reasons for testing the winding insulation.

About 40 different test methods are presently used to asses the condition of stator winding insulation [1,3-7]. Some of the frequently used test methods are insulation resistance measurement [4,7], high voltage AC/DC testing, Off line partial discharge testing and on line partial discharge monitoring [6,7], loss tangent and capacitance measurement [6,7], DC ramp testing [3] and response measurements in time and frequency domain [5]. Almost all of these tests are used for monitoring the symptoms of the deterioration of the insulation and maintenance engineers use the results of the testing to evaluate the condition of the insulation and to estimate the risk of failure of

Eng. (Prof.) M.A.R.M. Fernando, B.Sc. Eng. (Peradeniya), C. Eng., MIE (Sri Lanka), SMIEEE, Tech Lic. (KTH), PhD

(Chalmers), Senior Lecturer, Department of Electrical $\mathcal{E}$ Electronic Engineering, University of Peradeniya.

Eng. G.A. Jayantha, B.Sc. Eng. (Peradeniya), C. Eng., MIE (Sri Lanka), Chief Engineer, Assets Management, Ceylon Electricity Board, Kandy. 
the operating unit. Use of all the test methods is time consuming and it requires a longer period of outage which finally counts in terms of cents and rupees.

Best example is that the response measurements such as frequency dielectric spectroscopy (FDS) and polarization, depolarization current (PDC), provides useful information.

However, it usually takes 3-4 hours to see the real effect of the insulation by either going below $\mathrm{mHz}$ range or above $1000 \mathrm{~s}$ in frequency and time domains respectively. On the other hand, DC ramp test also provide useful information and due to its simplicity, this test can be conducted in the field very easily.

Authors wish to elaborate on condition assessment of generator stator insulation aiming to understand the use of DC ramp test especially to diagnose the presence of moisture. Results of field test and laboratory test by different test methods are used to establish a relationship among the test results and testing methods.

\section{Theoretical Investigations}

\subsection{Generator Stator insulation}

Main purpose of the insulation of the stator winding is to avoid short circuit between phases and between phase and ground. It has to transmit heat due to conductor current to the out side of the winding insulation (to the cooling medium and the stator core). Strand insulation, turn insulation and groundwall insulation are the three main basic constitutes of the stator insulation system as shown in Figures 1 and 2.

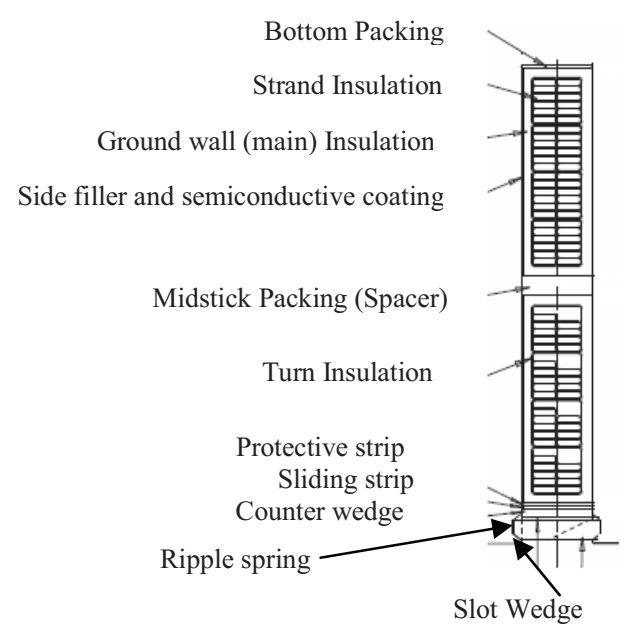

Figure 1 - Cross section of stator winding in a slot

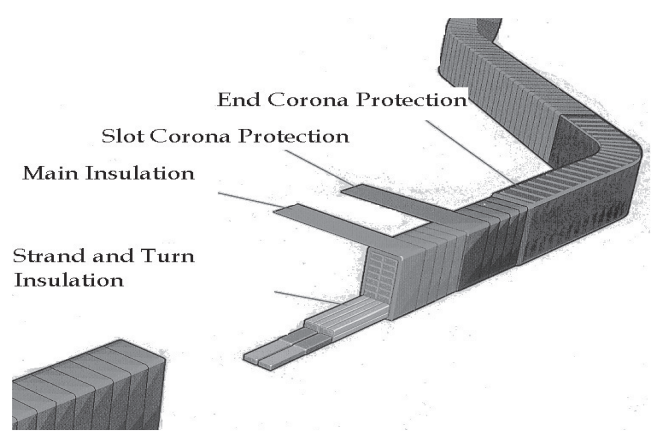

Figure 2 - Insulation of stator winding

According to the insulation material and bonding agent of the main insulation (Ground wall insulation), the insulation of generator stator windings can be classified in to three main versions as asphalt- mica, polyester- mica and epoxy-mica. Mica is the main insulation material [8].

The generator stator insulation, as a dielectric material, when subjected to an electric stress by ac or DC voltage, current flows from the cu conductor to the outer insulation or to the ground wall. This current consists of two parts i.e. surface leakage and current through the insulation. The current through the insulation is mainly characterized by the capacitive, leakage and the polarization behaviour of the insulation and can be estimated using empirical formulas. On the other hand, the surface current can not be estimated but could be separated by measuring with or/and without the guarding electrode. In general, the behaviour of the insulation (dielectric material) can be analysed in time or frequency domains depending on the supply voltage of DC or ac respectively [9].

\subsection{Time Domain analysis}

In time domain analysis, the insulation is subjected to a DC voltage and the response is recorded with respect to the time. The time variation of current can be obtained from the expression for current density according to the Maxwell's equations

$J(t)=\nabla \wedge H=\sigma E+\varepsilon_{0} \frac{\partial E}{\partial t}+\frac{\partial P}{\partial t}-$

Where $\mathrm{E}$ and $\mathrm{P}$ are electric stress and polarization. The first, second and third terms represent the contribution from conduction, capacitive and polarization currents respectively. The polarization has contribution from rapid and slow phenomena as 


$$
P(t)=\varepsilon_{0}\left(\varepsilon_{\infty}-1\right) E(t)+\varepsilon_{0} \int_{0}^{t} f(\tau) E(t-\tau) d \tau-(2)
$$

Where $f(t)$ is the response function of the material. By combining eqv (1) and (2), the current density can be written as

$$
J(t)=\sigma E(t)+\varepsilon_{0} \frac{\partial}{\partial t}\left[\varepsilon_{\infty} E(t)+\int_{0}^{t} f(\tau) E(t-\tau) d \tau\right](3)
$$

When a voltage $\mathrm{U}(\mathrm{t})$ is applied, the current is

$$
I(t)=\frac{C_{0} \sigma U(t)}{\varepsilon_{0}}+C_{0} \frac{\partial}{\partial t}\left[\varepsilon_{\infty} U(t)+\int_{0}^{t} f(\tau) U(t-\tau) d \tau\right](4)
$$

Where the $\mathrm{C}_{0}$ is geometric capacitance. By measuring the current one could separate capacitive, conduction and polarization components.

\subsubsection{DC ramp test}

In this method, the DC voltage is ramped up (usually at a low rate like $1 \mathrm{kV} / \mathrm{min}$ ) while the current is continuously monitored as a function of voltage (I-V characteristics). Due to simplicity, better assessment and applicability of interrupting the test during abnormal conditions, this test can be effectively used for condition assessment of rotating machines $[3,10]$. In our work, attention has been paid to use this test method effectively and some of our previous findings have been reported in [11].

If the slope of voltage is $\alpha$ (i.e. $U(t)=\alpha t$ ), the leakage and capacitive components can be approximated (according to eqv 4 ) as

$$
\begin{aligned}
& I_{\text {leak }} \approx \frac{C_{0} \sigma \alpha t}{\varepsilon_{0}}=\frac{\alpha t}{R} \\
& I_{\text {cap }} \approx C_{0} \varepsilon_{\infty} \alpha=C_{\infty} \alpha
\end{aligned}
$$

Where $\mathrm{R}$ is representation of resistance for leakage current and $\mathrm{C}_{\infty}$ is the capacitance at higher frequencies. By assuming that the response function $\left(f(t)=A t^{-n}\right)$ of the insulation follows Curie-Von Schweidler behaviour [9] the absorption current can be approximated as

$$
I_{a b s} \approx C_{0} A \alpha t^{1-n}=K C_{\infty} \alpha t^{1-n}
$$

Where $\mathrm{K}=\mathrm{A} / \varepsilon_{\infty}$.

Now the resultant current in DC ramp test can be written as

$$
I(t)=\alpha\left[\frac{t}{R}+C_{\infty}+K C_{\infty} t^{1-n}\right]
$$

Since the DC ramp test is conducted without the guarding terminal, the surface current is included in the measured ramp test results.
However, the surface current can be considered as small. By fitting the current values of eqv (9) with measured I-V curve the variables of $R, C_{\infty}$, $\mathrm{K}$ and $\mathrm{n}$ can be obtained. Figure 3 shows one example of DC ramp test conducted on Canyon Power Station Generator U-01 in 2008 January. The fitted curves comprising the contribution from capacitive, resistive and absorption components are included in the plot. The capacitive and leakage currents are respectively constant and linear. The estimated values are $\mathrm{R}$ $=3 \mathrm{~T} \Omega, \mathrm{C}_{\infty}=180 \mathrm{nF}, \mathrm{K}=3 \times 10^{4}$, and $\mathrm{n}=0.9$.

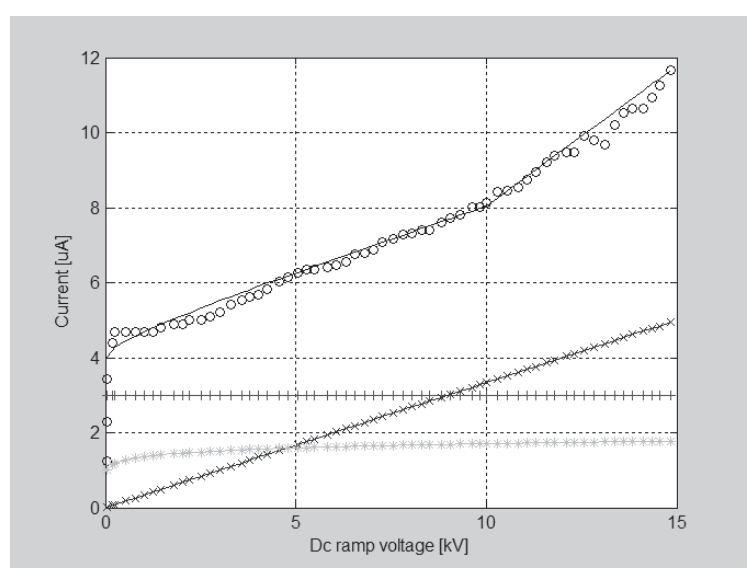

Figure 3 - Measured and fitted DC ramp test results for Canyon U-01 $R$ Phase (2008 January) [o for measured values, - for fitted values, + for capacitive current, * for absorption current, and $x$ for leakage current

\subsubsection{Polarization and depolarization current (PDC)}

The insulation is first subjected to a constant DC voltage $U$ and polarization (charging) current is measured over a long period i.e. 10000s. Then the insulation is short circuited and depolarization (discharging) current is measured. This test method despite time consuming, provides useful information about the insulation. The depolarization current directly follows the response function $\mathrm{f}(\mathrm{t})$ as

$$
f(t) \approx \frac{I_{\text {depol }}(t)}{C_{0} U}(10)
$$

If the insulation is charged sufficiently longer period i.e. at least $1000 \mathrm{~s}$, the conductivity $(\sigma)$ can be approximated as the difference between polarization and depolarization current

$$
\sigma \approx \frac{\varepsilon_{0}}{C_{0} U}\left[I_{p o l}(t)-I_{\text {depol }}(t)\right]
$$

Figure 4 shows one example of polarization depolarization test conducted on a polyester spare winding taken from Ukuwela power station. The response function was calculated according to eqv 10 and is included there. The 
test voltage was $100 \mathrm{~V}$. The conductivity was calculated (at $27^{\circ} \mathrm{C}$ ) and was $6.55 \times 10^{-12} \mathrm{~S} / \mathrm{m}$.

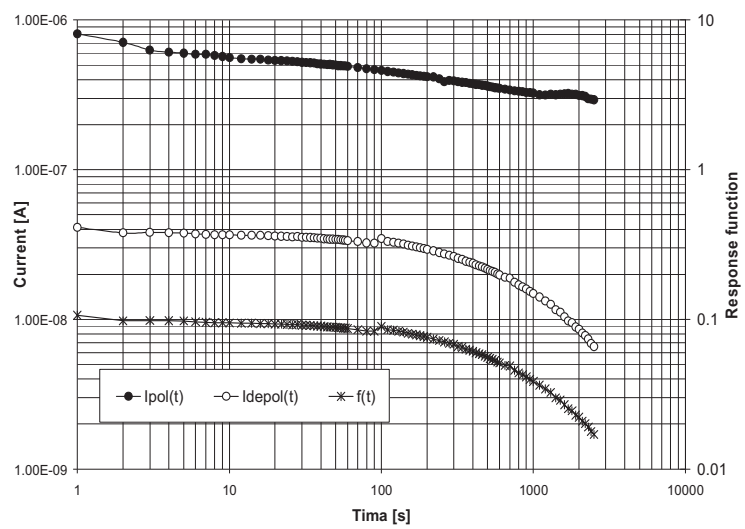

Figure 4 - Polarization/Depolarization current and response function for a spare winding from Ukuwela Power station (age 35 years)

\subsubsection{Insulation resistance (IR)}

Here a constant DC voltage i.e. $5 \mathrm{kV}$ is applied to the insulation. Traditionally IR at one minute and IR at 10 minutes are measured. The winding temperature, ambient temperature and humidity at the time of testing are recorded. IR values at one minute depend on the temperature of the winding and humidity of the ambient conditions. The measurement shall be done above dew point and the results can be used to evaluate whether the winding insulation is OK for the normal operation and subsequent high voltage testing. The IR at 10 minutes is also measured to find the polarisation index PI (IR@10 minutes / IR@1 minute) which is independent of the temperature and it can be used to trend the results. In this work, by deviating from the traditional test method, the IR values were continuously monitored since they could easily be compared with DC ramp and polarization currents. Once the DC voltage is applied the capacitive current decays to zero very rapidly. So, time variation of IR can be correlated to DC ramp results and polarization current as

$$
I R(t)=\frac{1}{\frac{1}{R}+K C_{\infty} t^{-n}}=\frac{U}{I_{p o l}(t)}
$$

The surface current is not included here, but it can be measured by taking the difference between IR test with and without guarding terminal. Figure 5 shows the time variation of IR values with and without guarding terminal for a polyester mica spare winding taken from Ukuwela Power station at temperature $28^{\circ} \mathrm{C}$ and RH $66 \%$.

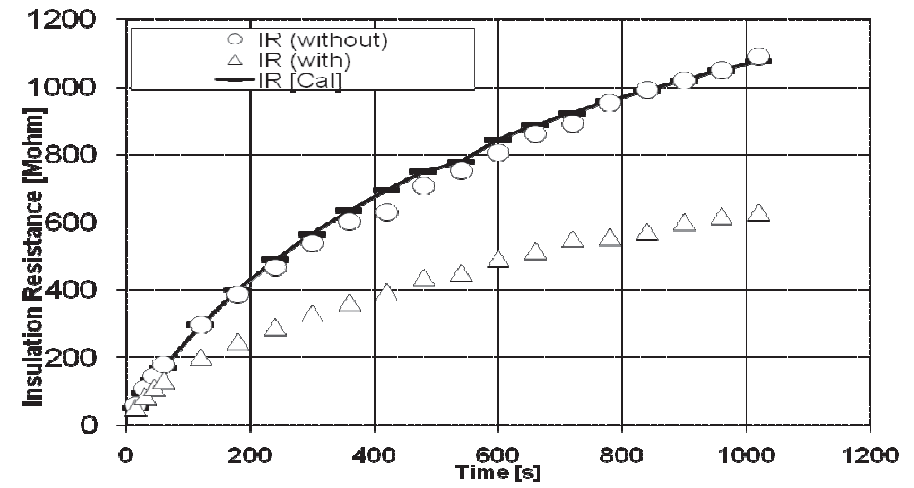

Figure 5 - IR results for polyester winding from Ukuwela power station (age 35 years) with and without guarding terminal (o for without surface current, $\Delta$ for with surface current, - for calculated current, $R=1950 \mathrm{G} \Omega$, $\mathrm{C}_{\infty}=1.8 \mathrm{nF}$

\subsection{Frequency Domain analysis}

In frequency domain analysis, ac voltages at different frequencies are applied to the insulation and their corresponding currents are recorded. When transforming the current density in eqv (3) into frequency domain, the convolution becomes the product as

$$
J(\omega)=\sigma E(\omega)+\varepsilon_{0} j \omega \varepsilon_{\infty} E(\omega)+\varepsilon_{0} f(\omega) E(\omega)
$$

By defining the complex susceptibility as the Fourier transform of response function $f(t)$ as in eqv (14).

$\chi(\omega)=f(\omega)=\chi^{\prime}(\omega)-j \chi^{\prime \prime}(\omega)(14)$

At a voltage of $U(\omega)$, the corresponding current can be written

$I(\omega)=j \omega C_{0}\left[\left\{\varepsilon_{\infty}+\chi^{\prime}(\omega)\right\}-j\left\{\frac{\sigma}{\omega \varepsilon_{0}}+\chi^{\prime \prime}(\omega)\right\} U(\omega)\right.$

\subsubsection{Capacitance and loss tangent}

In frequency domain, separation of currents is difficult. Instead capacitive and loss tangent values are used. By introducing complex permittivity to the eqv (15), the current can be simplified as

$$
\begin{aligned}
I(\omega) & =j \omega C_{0}\left[\varepsilon^{\prime}(\omega)-j \varepsilon^{\prime \prime}(\omega)\right] U(\omega) \\
& =j \omega\left[\left(C^{\prime}(\omega)-j C^{\prime \prime}(\omega)\right)\right] U(\omega)
\end{aligned}
$$


Then the loss tangent is given by

$$
\tan (\delta)=\frac{C^{\prime \prime}(\omega)}{C^{\prime}(\omega)}=\frac{\frac{\sigma}{\omega \varepsilon_{0}}+\chi^{\prime \prime}(\omega)}{\varepsilon_{\infty}+\chi^{\prime}(\omega)}(17)
$$

Traditionally, the capacitance $\left(\mathrm{C}^{\prime}\right)$ and loss tangent at power frequency $(50 \mathrm{~Hz})$ is used for evaluation of the insulation which provides a rough estimation on its condition.

\subsubsection{Frequency Dielectric Spectroscopy (FDS)}

FDS measurements are widely used for condition assessment of high voltage apparatus alternative to the single point measurements i.e. as in part 2.3.1. From recently FDS measurements have been introduced to rotating machines [5]. In this method, complex capacitance and loss tangent values are measured up to low frequencies. In our work, FDS measurements were taken from $1 \mathrm{kHz}$ to $0.1 \mathrm{mHz}$. Figure 6 shows frequency variation of complex capacitance for polyester spare winding from Ukuwela power station. The $C^{\prime}$ usually increases with the decreases of frequency as shown in the figure. The general tendency of $C^{\prime \prime}$ is increasing towards a loss peak with the reduction of the frequency. The loss tangent and the power factor were calculated and are included in the graph. When loss tangent values were low, it is approximately equals to the power factor (i.e. $\left.\tan \delta \approx \sin \delta=\sin \left(90^{\circ}-\phi\right)=\cos \phi\right)$.

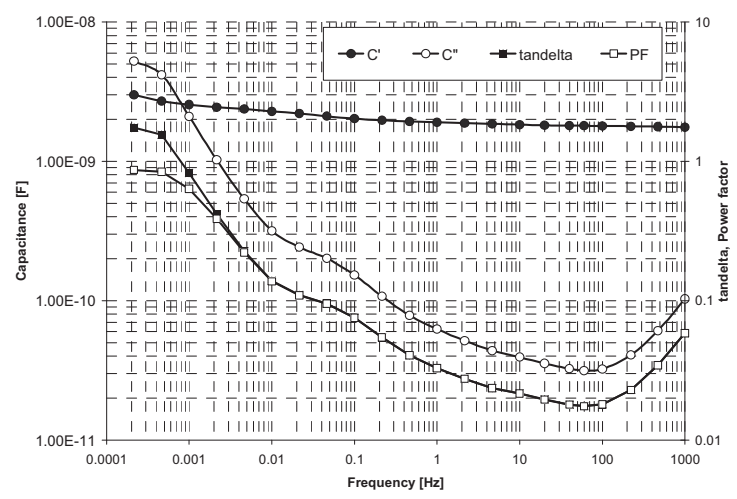

Figure 6 - Frequency variation of $C^{\prime}, C^{\prime \prime}$, loss tangent and power factor for spare winding for Ukuwela power station (Age 35 years)

\subsection{Partial Discharge (PD) Test}

Partial discharge is a localized electrical discharge in an insulation system that does not completely bridge the electrodes. In rotating machines where rated operating voltage is higher than $2-3 \mathrm{kV}$, this phenomenon normally occurs and monitoring can be done in both offline and on-line using various PD sensors (Couplers) and monitoring equipment. Most of the techniques measure current and voltage pulses that arises due PD in the winding insulation. On line monitoring of the PD is popular among the utilities due to the reason that the measurement gives a realistic condition of the insulation at its normal operation conditions.

The PD measurement can be used to determine the deterioration of insulation system due to insulation delamination, voids, slot discharges, discharges at the end windings and damages to stress grading insulation. It can be used as an acceptance test of individual coils and new generators which helps to assess the manufacturing process and the status of curing of the winding after manufacturing.

PD is a pulse with short duration (i.e. in ns) so that a device sensitive to high frequencies is used to detect PD. Typically, HV capacitors $(80 \mathrm{pF}-1000 \mathrm{pF})$ connected to the live phase terminals of the rotating machines are used as the couplers by modern on-line monitoring systems. PD results are usually presented mainly by magnitude of the highest PD pulse (Qm - units in $\mathrm{pC}$ or $\mathrm{mV}$ ). In addition, modern pulse count rate (in pulses per Second, ppS) and the phase angle are also used.

Figure 7 and 8 show PD measuring setup and test results obtained from the Generator U-01 of Ukuwela power station which has polyester mica insulation.

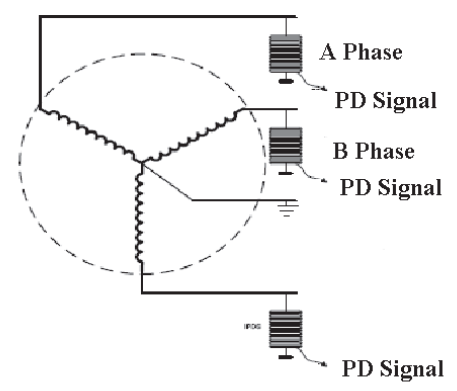

Figure 7 - Basic arrangement of sensors for on line PD measurements. Two couplers were used for noise filtering and the coupling capacitance is $80 \mathrm{pF}$ 


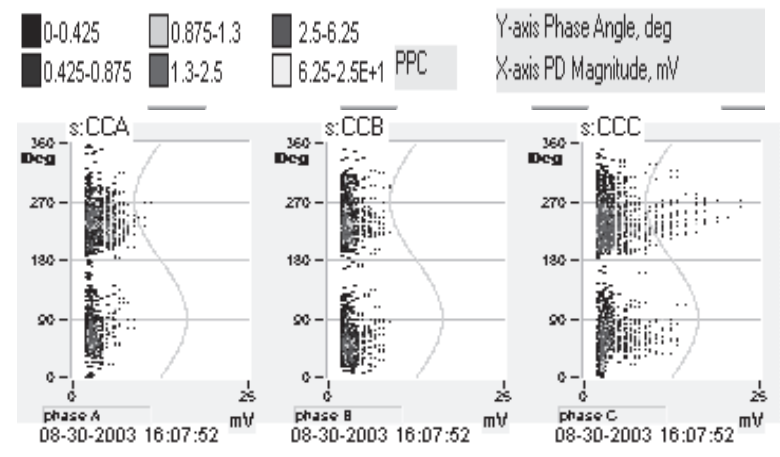

Figure 8 - Phase Resolved data obtained by capacitor couplers on Phase A, B, C. Pulse repetition rate is given by different colours as in the legend

\subsection{Comparison}

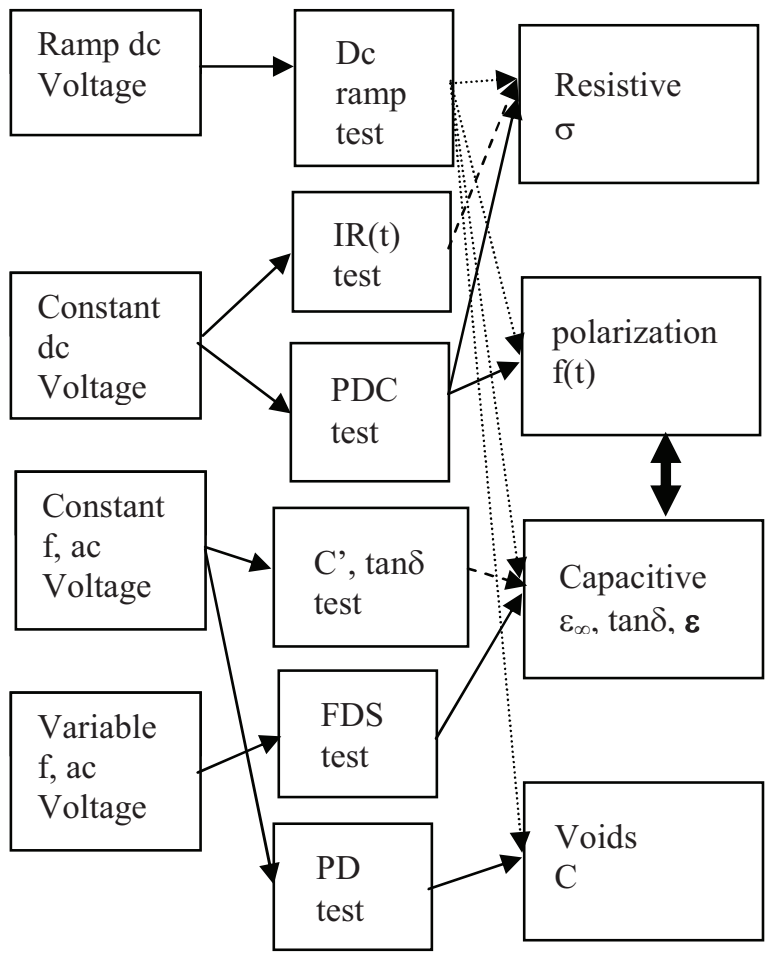

Figure 9 - Comparisons of test methods

Out of different parameters, the response function $f(t)$, conductivity $(\sigma)$, capacitance at higher frequency $\left(\varepsilon_{\infty}\right.$ or $\left.\mathrm{C}_{\infty}\right)$, loss tangent at $50 \mathrm{~Hz}$ provides the overall picture of the insulation. The PDC results directly provides the values of $f(t)$ and $\sigma$ whereas FDS results gives $\varepsilon_{\infty}$ and $\tan \delta$ values. However, time domain results can be verified with that in frequency domain and vice versa using Fourier transform or inverse Fourier transform respectively [9]. Similarly, the DC ramp test results can be modelled and verified with time and frequency domain results. A summery of comparison of different test methods is shown in Figure 9. In this study under laboratory investigations (part 3), attention was paid to validate the DC ramp test results with corresponding PDC and FDS values. With those correlations, the DC ramp test could be effectively used to interpret the field measurements in part 4.

\section{Laboratory Investigations}

\subsection{Details of Winding samples}

Four spare winding samples were collected from hydro generators for comparison of different test methods under different moisture conditions. Their details are as follows:

W1 - A $11 \mathrm{kV}$, asphalt mica spare winding from Wimalasurendra Hydro Power station (WPS) with an ageing time of 52 years. This winding was found in the stores of the power station without any packing or precautionary measures to protect the winding and was considered as a "wet" sample.

W2 - A $12.5 \mathrm{kV}$ asphalt mica spare winding from Samanala Hydro power Station (SPS) with an ageing time of 40 years. This winding was found in the stores of the power station with packing and was considered as a "Dry" sample.

W3 - A $12.5 \mathrm{kV}$, polyester mica spare winding from Ukuwela Hydro Power station (UK) with an ageing time of 36 years. This winding has been stored in good condition and considered as a "dry" sample.

W4 - A $13.8 \mathrm{kV}$ epoxy mica used winding from Kotmale Hydro Power Station with an ageing time of 22 years. The sample was a half section of a winding removed from service in year 2000 and considered as a "dry" sample.

\subsection{Test Setup}

Each winding sample was prepared for testing. The windings were kept horizontal on top of an insulating sheet on top of four stools. The two conductors were connected together as the "HV" terminal. Both parts of the ground wall insulation were connected together as the "LV" terminal. Preliminary studies were conducted with different types of terminal connections for the ground wall insulation in order to represent the effect of the core in real generators. They included (i) a closely wound Al conductors (10 turns of $2.5 \mathrm{~mm}$ diameter), (ii) an $\mathrm{Al}$ sheet (0.5mm thickness) and (iii) wound $\mathrm{Al}$ 
conductors on $\mathrm{Al}$ sheet). It was found that the configuration for the LV terminal had negligible effect on the overall measurements. Thus configuration mentioned as (iii) was used for final measurements. The third electrode, i.e. the guarding terminal was used by connecting the potential grading insulation of the winding. A schematic diagram of the test set-up for FDS measurements is shown in Figure 10. The same configuration was used in other test methods except PD.

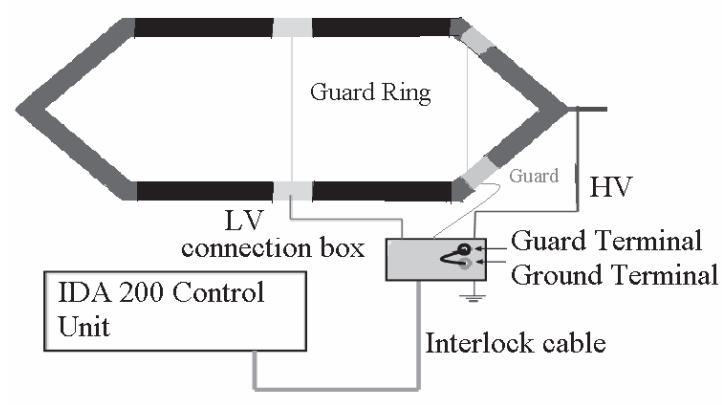

Figure 10 - Test set-up for laboratory measurements

\subsection{Procedure}

Different test methods were used in this study. They were DC ramp, IR, PDC, FDS and PD tests. In DC ramp test, the voltage was increased from 0 to $15 \mathrm{kV}$ at a rate of $1 \mathrm{kV} / \mathrm{min}$ and the I-V signature was noted using DCR50 Adwel DC ramp tester. The IR test was conducted at $5 \mathrm{kV}$ by using a Megger and the IR values were continuously monitored for 2500 seconds. In PDC test, the windings were charged for $1250 \mathrm{~s}$ at $50 \mathrm{~V}$ and discharged for 1250s. The corresponding currents were recorded using Keithly Electrometer 6517A. In FDS measurement, frequency variation of complex capacitance and loss tangent were measured using IDA 200 at $200 \mathrm{~V}$ from $1 \mathrm{kHz}$ to $0.1 \mathrm{mHz}$. PD test was done using Insul Gard partial Discharge monitoring equipment and measurement was done in the frequency band of $1 \mathrm{MHz}$ to $20 \mathrm{MHz}$. Noise filtration is done by noise suppression algorithm.

Laboratory measurements were taken on each winding sample at room temperature $\left(24^{\circ} \mathrm{C}\right.$ $28^{\circ} \mathrm{C}$ ) and at relative humidity levels between $75 \%-90 \%$ in the following sequence. The DC ramp test was initially conducted till $15 \mathrm{kV}$. The following day IR test was conducted at $5 \mathrm{kV}$ for $1000 \mathrm{~s}$ and data were recorded in each $60 \mathrm{~s}$. With adequate relaxation, the FDS was conducted. PDC and PD tests were conducted on some of the samples.
After the preliminary measurements, two separate test sequences were followed; one with drying process on wet windings W1 and W2, the other under wetting conditions for winding W3.

In the drying process, the samples were dried inside an oven $(2600 \mathrm{~mm}$ X $1700 \mathrm{~mm}$ X $800 \mathrm{~mm})$ for nearly three days. Similar process was adopted for drying Bowatenna generator which was submerged in water for more than 24 hours in December 1991 [12]. Initially, the oven temperature was increased from $29^{\circ} \mathrm{C}$ to $65^{\circ} \mathrm{C}$ at a rate of $5^{\circ} \mathrm{C}$ per hour. (Phase I). Then the oven temperature was increased to $80^{\circ} \mathrm{C}$ at the rate of $5^{\circ} \mathrm{C}$ per hour [4] and kept for 48 hours (Phase II). Finally the sample was allowed to cool naturally under closed condition of the oven for further 18 hrs (Phase III). DC ramp test and IR tests were conducted at the end of each heating process. The first measurements were taken in Phase I at coil temperature of $37^{\circ} \mathrm{C}$ after $23 \mathrm{hrs}$. The final measurements were taken at the end of Phase III at $29^{\circ} \mathrm{C}$ and relative humidity of $66 \%, 18 \mathrm{hrs}$ after shut down of the oven. After Phase III, FDS measurements were also taken for comparison.

W3 coil which was found be fairly dry was used for moisture injection process. Water ingress to the generator chamber of the Ukuwela generator had happened 2-3 times in mid 1990s due to heavy leakages from the generator cooling water lines. During the laboratory testing it was tried to simulate the same condition in the laboratory to investigate the moisture ingress to the winding. The coil was submerged up to the level of the semiconductive layer, which is similar to submerging the winding overhangs of the end winding of the generator stator winding. Testing of DC ramp and FDS continued at different time intervals.

\subsection{Results and Discussion}

\subsubsection{Effect of Drying}

Figures 11 and 12 show the DC ramp, and FDS results during drying process for $\mathrm{W} 1$. In all cases, removal of moisture from the winding was clearly indicated. In DC ramp test, the current levels at $15 \mathrm{kV}$ became low after drying and were comparable with dried windings. The initial current level at $15 \mathrm{kV}$ (i.e. $135 \mu \mathrm{A}$ ) dropped to $56 \mu \mathrm{A}$ after the phase I and it was $3.5 \mu \mathrm{A}$ at the end of test. In the IR tests, the charging currents dropped significantly (order of 500 times at 1000 s). The measured IR values 
at $5 \mathrm{kV}$ at one minute were $174 \mathrm{M} \Omega, 567 \mathrm{M} \Omega$ and $8.8 \mathrm{G} \Omega$ respectively. The corresponding PI values were 1, 1.6 and 4.1 respectively. The results in the frequency domain i.e. the FDS were also clearly showed reduction of $C^{\prime \prime}$ (losses) i.e. even up to order of 10 times) (see figure 12).

In comparison to $\mathrm{W} 1$, the same procedure was adopted for the asphalt dry winding (W2). No clear differences were observed either in DC ramp test or FDS results confirming that the W2 was in the "dry" condition.

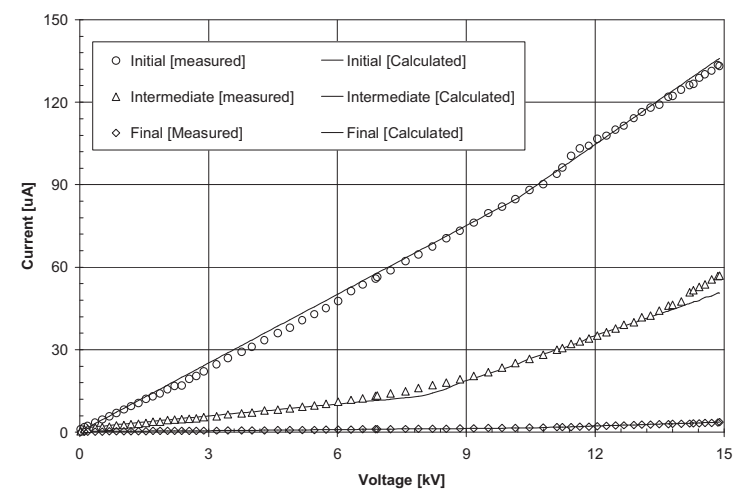

Figure 11 - DC ramp test results of W1 during drying process

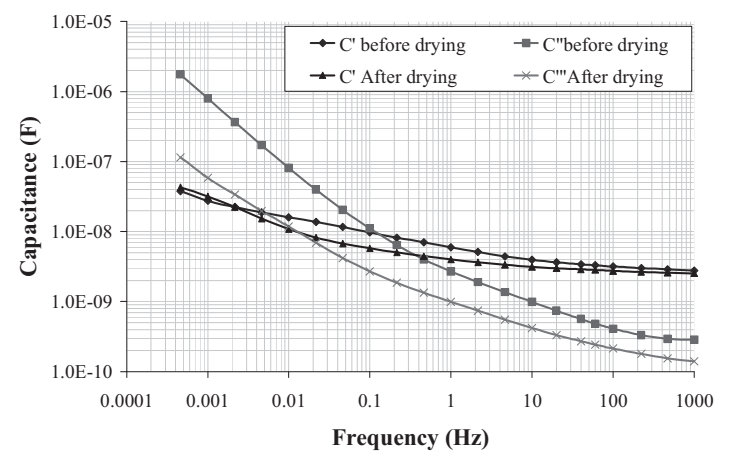

Figure 12 - FDS test results of W1 during drying process

\subsubsection{Effect of wetting}

Figure 13 shows the comparison of DC ramp test results for winding 3 at different intervals. Figure 14 shows the FDS results after one week of moisture ingress. According to DC ramp test results, the LC levels under ramped DC voltage increased during wetting. In comparison, a significant change in loss characteristics could be seen in FDS results. After wetting the loss peak shifted and indicated around $4 \mathrm{~Hz}$. However, the peak level is less significant. Similarly, the change in capacitance was less significant. Based on these facts, it is clear that polyester mica insulation need more time to become wet.

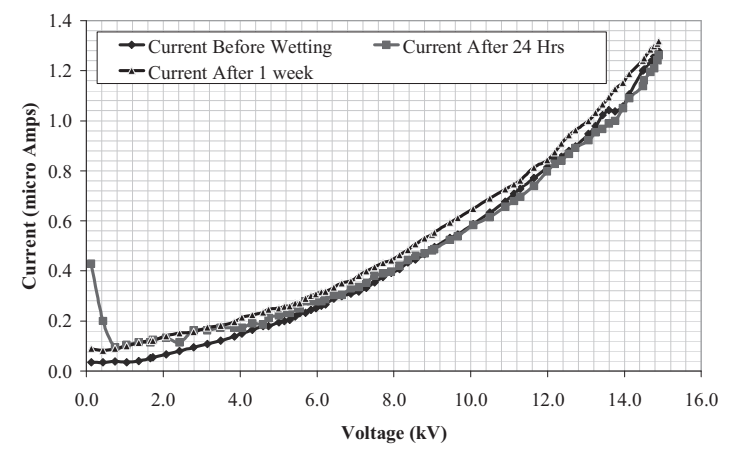

Figure 13 - DC ramp results for W3 during wetting

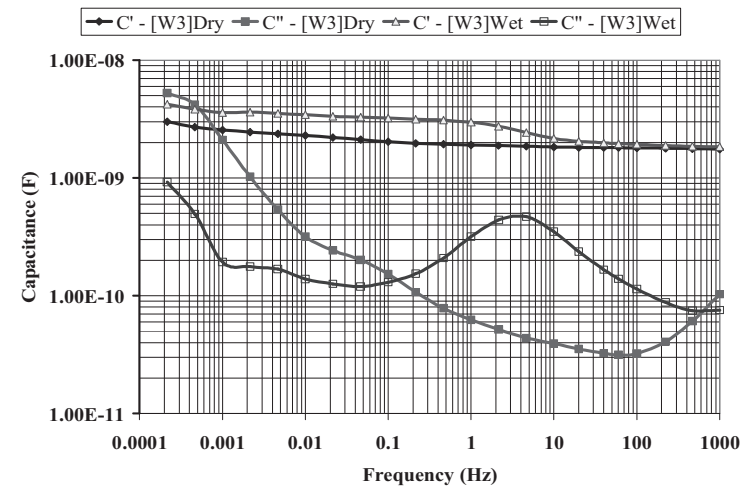

Figure 14 - FDS results for W3 during wetting

\section{Comparison of test methods}

Figure 15 shows the DC ramp test results for all four windings at the initial stage. The modelled curves are also included for the comparison. Figure 16 shows FDS results of each winding.

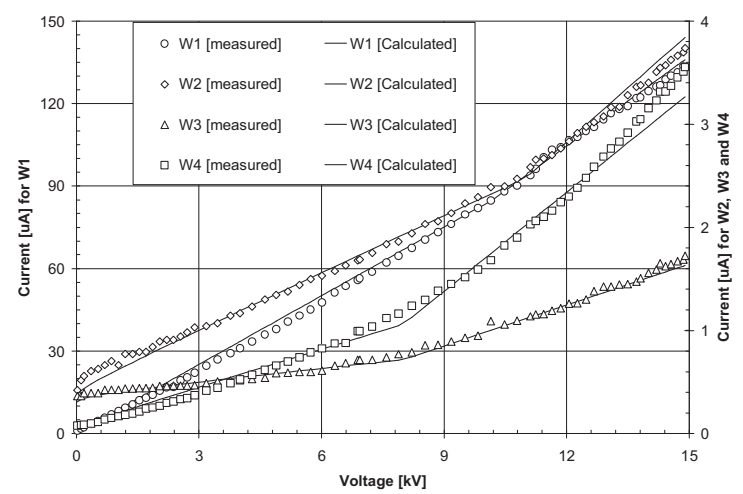

Figure 15 - DC ramp results of windings

In general, the tests were conducted in similar levels of room temperatures, i.e. $27-28^{\circ} \mathrm{C}$, so that results can be compared without considering the effect of temperature on dielectric materials. 


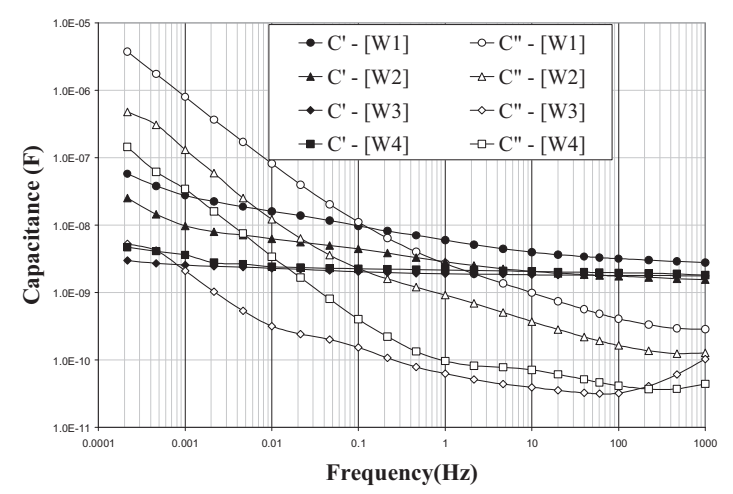

Figure 16 - FDS results for windings

By comparing different types of insulations (asphalt, polyester, epoxy), it is considered, epoxy is superior [8] and asphalt mica insulation is more prone to moisture ingress. The results also prove this for asphalt windings (W1 and W2) by obtaining higher leakage in DC ramp test and high losses in FDS test,

The comparison of capacitance at infinity provides useful information about the dimensions of the insulation as well as relative permittivity. The capacitance values calculated by fitting the DC ramp test results were in similar range with the measured $C^{\prime}$ in FDS test.

\section{Field Investigation}

The periodic DC ramp tests are conducted on generators during their annual maintenance period. In this work, some generators with different types of insulation (asphalt, polyester and epoxy) were selected and details are given in Table 1. Some extracted cases are illustrated below.

Table 1- Details of the tested generator windings

\begin{tabular}{|c|c|c|c|c|}
\hline Station & $\begin{array}{c}\mathrm{S} \\
{[\mathrm{MW}]}\end{array}$ & $\begin{array}{c}\mathrm{V} \\
{[\mathrm{kV}]}\end{array}$ & Insulation & Year \\
\hline WPS & 25 & 11 & Asphalt & 1957 \\
\hline Samanala & 37.5 & 12.5 & Asphalt & 1969 \\
\hline $\begin{array}{c}\text { New } \\
\text { Laxapana }\end{array}$ & 50 & 12.5 & Polyester & 1972 \\
\hline Ukuwela & 20 & 12.5 & Polyester & 1973 \\
\hline Bowathenna & 40 & 11 & Polyester & 1980 \\
\hline Kelanitissa & 20 & 11 & Epoxy & 1982 \\
\hline Randenigala & 60 & 12.5 & Epoxy & 1985 \\
\hline Kotmale & 67 & 13.8 & Epoxy & 1986 \\
\hline
\end{tabular}

4.1 Kelanitissa turbo generator (Moisture absorption)

Effect of cleaning and drying was studied in one of the turbo generators of 20MW capacity at Kelanitissa Gas turbine power station and results are shown in Fig 17. In 2009, this generator tripped with earth fault indication. At the time of tripping it was raining heavily. (Cooling system of the generator is an open system using out side air. Out side air was taken through a filter and after cooling of the generator the air was released to the atmosphere).

Insulation resistance measurement was not possible since the IR at 500V DC indicate Zero. DC ramp test was done on May 11, 2009. Sudden up turn of the leakage current was observed during the first measurement just after the generator tripped due to earth fault. The test was interrupted at $0.97 \mathrm{kV}$. (results is indicated as 11-05-2009.

Generator stator winding was cleaned after removing rotor (duration of cleaning was eight days) and the generator was tested again using DC ramp test on May 18, 2009. Even after cleaning the winding for eight days, non linear pattern was shown in the DC ramp test results as indicated as 18-05-2009 confirming considerable moisture absorption in the winding. Drying of the winding continued until the leakage current curves almost overlapped. Final leakage current at winding temperature of $38{ }^{\circ} \mathrm{C}$ was $21.8 \mu \mathrm{A}$ at $14.81 \mathrm{kV}$. The corresponding insulation resistance (IR@ one minute) reading was $679 \mathrm{M} \Omega$. DC ramp test results during the drying of the winding on June 03, 2009 and June 17, 2009 are also included in the figure.

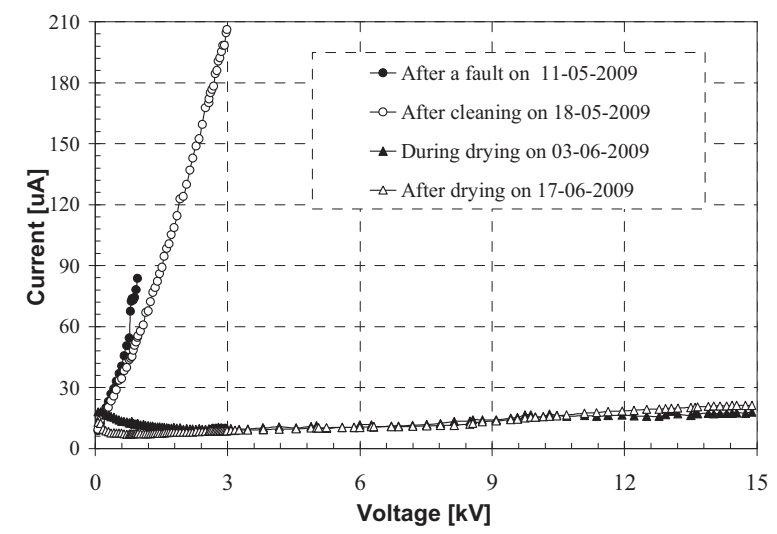

Figure 17 - DC Ramp Test results of GT4 'R' Phase 


\subsection{Kotmale Generator (Change of excitation)}

Kotmale U01 generator had been operated with static excitation system for more than 15 years. During this period the generator windings were required to be cleaned regularly due to the deposition of carbon dust. Excitation was changed to brushless in 2008 and Figure 18 shows the DC ramp test results during 2007 and 2009. The results indicate a significant change current (mainly the capacitive component) due to improvement of dryness of the generator windings.

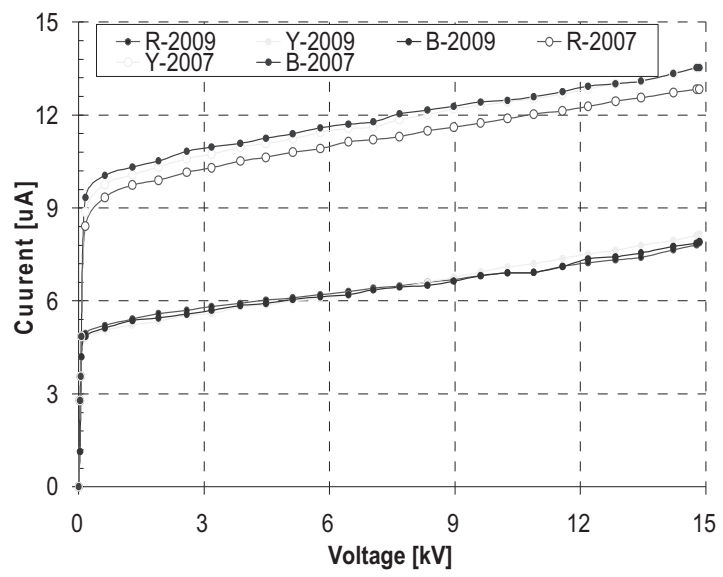

Figure 18 - DC ramp test results of Kotmale Unit 01 Generator during 2007 and 2009 on RYB phases.

\subsection{Wimalasurandra generator}

Figure 19 shows the DC ramp test results for Wimalsurendra generator during 2008 (51 years) and 2010 (53 years). It is interesting to note that asphalt mica insulation aged for more than 50 years showed comparatively good current levels in the DC ramp test. The laboratory tested winding (W1) which was dried about three days is also shown in the figure for comparison. In WPS generator, 14 windings are connected in series and three such parallel units are connected to one phase. So, I$\mathrm{V}$ curve for single winding was modified to represent the generator (42 times of the current). According to the figure, the estimated current level for the dried winding was higher than the measured current of the generator confirming that moisture absorption was not fully evaporated and still need longer period in the drying process. At the same time, the capacitive current components (winding and the generator) seem to be in the same order.
When comparing the test results during 2008 and 2010, no significant change observed. Further periodic testing and investigation of the trend will provide the ageing effect of the winding.

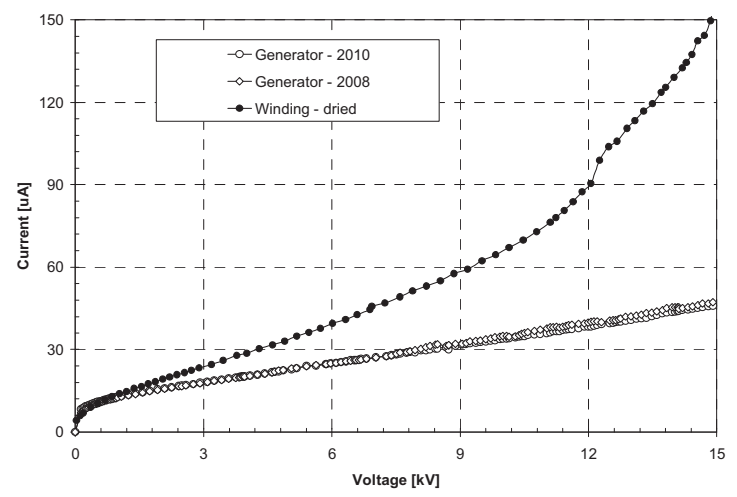

Figure 19 - DC ramp test results of Wimalasurendra generator

\section{Summery and Conclusions}

Moisture absorption in stator winding is one of the main reasons for generator failures. When moisture is present, the resistance of the stator insulation drops, alternatively, leakage current activity increases. Accordingly, leakage current through the insulation becomes high in DC ramp and polarization/depolarization (PDC) tests. Similarly, loss tangent increases in frequency dielectric spectroscopy (FDS) test whereas partial discharge (PD) test shows increase PD level. Thus in this study, attention was paid to test different generator windings under different moisture conditions and to investigate their performances with different test methods i.e. DC ramp, PDC, IR, FDS and PD tests.

The leakage current through the insulation is characterized by its capacitive, resistive and polarization components. Accordingly, relative permittivity $\left(\varepsilon_{\infty}\right)$, conductivity $(\sigma)$ and the response function $(f(t))$ or tan $\delta$ (combine $\sigma$ and $\mathrm{f}(\mathrm{t})$ ) are the key parameters describing the state of the insulation. The PDC test provides direct correlation to $\sigma$ and $\mathrm{f}(\mathrm{t})$, whereas $\tan \delta$ and $\varepsilon_{\infty}$ can be easily found from FDS test. However, when the I-V signature of DC ramp test is properly modelled and fitted with the different current components, the key parameters such as $\varepsilon_{\infty}, \sigma$, and $\mathrm{f}(\mathrm{t})$ can be numerically evaluated. Thus one could use DC ramp test as a simple and effective field test to evaluate the condition of generator insulation. It is suggested that periodic testing the DC ramp during the annual 
maintenance period will provide a record of the state of the insulation and careful observation of the variation of the above parameters may provide a clear picture about future usage. In this paper, the authors elaborate the usage of DC ramp test in condition assessment by an extensive laboratory investigation on generator winding samples and several case studies in the field.

\section{References}

1. Stone, G. C., Boulter, E. A., Culbert, I., \& Dhirani, H., Electrical Insulation for Rotating MachinesDesign, Evaluation, Ageing, Testing and repair, IEEE Press, ISBN 0-471-44506-1, 2004

2. IEEE Std 95-2002, IEEE Recommended Practice for Testing Insulation Testing of AC Electric Machinery (2300V and Above) with High Direct Voltage, 2002.

3. Rux, L., \& Dermid, B. Mc., "Assessing the Condition of Hydro-Generator Stator Insulation Using the Ramped High Direct-Voltage Test Method", IEEE Electrical Insulation Magazine, Vol. 17, No.6, 2001, pp. 27-33.

4. IEEE Std 43-2000, IEEE Recommended Practice for Testing Insulation Resistance of Rotating Machinery, 2000.

5. Farahani, M., Borsi, H., \& Gockenbach, E. "Dielectric Response Studies on Insulating System of High Voltage Rotating Machines", IEEE Trans. on Dielectrics and Electrical Insulation, Vol. 13, No.1, Feb. 2006.

6. Emery, E.T., "Partial Discharge, Dissipation Factor, and Corona Aspects for High Voltage Electrical Generator Stator Bars and Windings", IEEE Trans. on Dielectrics and Electrical Insulation, Vol. 12. No. 2, April 2005, pp. 347-361.

7. Kaufhold, M., Schafer, K., Bauer, K., Bethge, A., \& Risse, J., "Interface Phenomena in Stator Winding Insulation - Challengers in Design, Diagnostics and Service Experience", IEEE Electrical Insulation Magazine, Vol. 18. No. 2, March/April 2002, pp. 27-36.

8. Boulter, E.A., \& Stone, G.C., "Historical Development of Rotor and Stator Winding Insulation Materials and Systems", IEEE Electrical Insulation Magazine, Vol. 20, No. 3, May/June 2004, pp. 25-39.

9 Jonscher, A. K., Dielectric Relaxation in Solids, Chelsea Dielectrics Press, London UK, ISBN 09508711-0-9, 1983.
10. David, E., Godin, T., Bellemare J., \& Lamarre, L., "Modelling of the Dielectric Response of a Stator Winding Insulation from a DC Ramp Test", IEEE Trans. on Dielectrics and Electrical Insulation, Vol. 14, No. 6, Dec. 2007, pp. 1548-1558.

11. Jayantha, G.A., Fernando, M.A.R.M., \& Ekanayake, C.M.B., "Evaluation of the Condition of Ground Wall Insulation of Generator Stator Winding Using DC Ramp Test - Experience on CEB Hydro Generators", Trans. of the Institution of Engineers (SL), 2009.

12. CEB Report on Bowatenna Power Station Rehabilitation Project, Repairing \& Commissioning of Generator, Volume 3.

\section{Acknowledgement}

The authors would like to express their deep gratitude to CEB and University of Peradeniya to conduct the tests and providing winding samples. 
